\title{
SONNFTS AND POEMS OF ANTHERO DE QUENTAL
}

TRANSLATED BY

S. GRISWOLD MORLEY 



\section{SONNETS AND POEMS OF ANTHERO DE QUENTAL}

TRANSLATED BY

S. GRISWOLD MORLEY

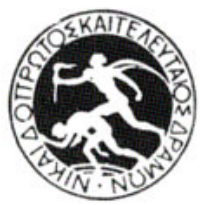

UNIVERSITY OF CALIFORNIA PRESS

BERKELEY, CALIFORNIA

I922 
Copyright, I922

BY

S. Griswold Morley 
To

DRUSILLA MORLEY 
